УДК 519.81

Наталія Олександрівна Королюк (кандидат технічних наук) ${ }^{1}$

Сергій Миколайович Лістровий ${ }^{2}$

Микола Ігорович Щербаков ${ }^{3}$

${ }^{1}$ Харківський національний університет Повітряних Сил ім. І. Кожседуба, Харків, Украӥна
${ }_{2}$ в/ч А2100, Київ, Украйна
${ }^{3}$ в/ч А0334, Дніпро, Украӥна

\title{
ПІДХІД ЩОДО ПРОГНОЗУВАННЯ ПОКАЗНИКІВ ЯКОСТІ ПЕРСПЕКТИВНИХ ЗРАЗКІВ ОЗБРОЄНЬ В УМОВАХ НЕСТОХАСТИЧНОÏ НЕВИЗНАЧЕНОСТІ
}

\begin{abstract}
Розглядається процес визначення прогнозних значень показника якості зразка озброєння на довгочасну перспективу, щуо передбачає врахування умов нечіткого середовища, яке формується природною $і$ поведінковою нестохастичними невизначеностями та невизначеністю мети операції. Функцію приналежності особа, щуо приймає рімення, визначає виходячи із ії відповідності фізичному змісту показника. Чисельна міра невпевненості експертів щзодо висловлювання своїх суб'єктивних думок визначається параметром функиії приналежності, який описує ї̈ “розмитість”. В якості інтервала прогнозних значень пропонуються чіткі підмножини носіїв значень показників. Обгрунтований фізичний зміст виду функиії приналежності та параметру ї̈ “розмитості” нечіткої підмножини, яка відповідає показнику якості, який розглядається, та в визначені чіткого інтервалу його прогнозних значень на момент часу при прийнятому рівні довіри за значенням функиії приналежності.
\end{abstract}

Ключові слова: довгочасне прогнозування, показники якості, зразки озброєнь, нестохастична невизначеність.

\section{Ветуп}

Оборонний характер воєнної доктрини Збройних Сил України (ЗСУ) висуває високі вимоги до всіх елементів бойової готовності і підготовки військ. Збройні Сили повинні бути готові відбити агресію шляхом ведення оборонних дій. Найважливішою задачею командування при оборонному характері воєнної доктрини стає постійне спостереження за противником, яке повинне забезпечити своєчасний і організований перехід військ 3 мирного на воєнний стан. Основою підтримання боєздатності ЗСУ планування їx розвитку в залежності від прогнозованих можливих воєнних загроз, що включає до себе визначення та розробку на основі принципу оборонної достатності основних напрямів i до в гострокового плану розвитку озброєння та військової техніки (ОВТ). Потреба у формуванні цих документів є об'єктивною. Адже жодна цивілізована країна не може якісно будувати власні збройні сили, не маючи достатньо окресленого їх обрису принаймні на 10-15 років [1]. Помилки при визначенні основних напрямів розвитку озброєння на етапі довгострокового планування можуть призвести до відставання якісних показників зразків, комплексів та систем озброєння від закордонних аналогів та до нераціонального витрачання коштів на заходи щодо оснащення збройних сил [2]. Розробка основних напрямів розвитку озброєння грунтується на комплексі прогнозів майбутнього розвитку воєнно-політичної обстановки, науковотехнологічної, промислової бази та ін., а стосовно озброєння та військової техніки його можливого кількісного та якісного стану. За часів Радянського Союзу довгострокові прогнози розвитку ОВТ здійснювалися, в основному, експертними методами на основі аналізу світових тенденцій розвитку ОВТ, необхідності створення зразків для усунення або попередження відставання від розробок ймовірного противника та виходячи 3 останніх досягнень науки i техніки щодо можливості створення якісно нових систем озброєння. 3 початку існування ЗС України питання удосконалення методологічного апарату довгострокового планування та розробки математичного апарату підтримки прийняття управлінських рішень не розглядалися у повному обсязі, тому рішення щодо оснащення ЗС України сучасними зразками ОВТ на даний час приймаються шляхом застосування евристичних або експертних процедур. Однак складність сучасних систем озброєння, що мають достатньо тривалі етапи життєвого циклу (ЖЦ), зокрема розробки, обумовлює високу відповідальність за прийняття управлінських рішень та потребує проведення досліджень щодо техніко-економічної оцінки перспективних бойових броньованих машин (ББМ) і прогнозу їх відповідності майбутнім загрозам. Без цього можливе 
нераціональне або навіть нецільове витрачання коштів. Саме тому в сучасних умовах науковометодичний апарат (НMA) прогнозування розвитку ОВТ, зокрема ББМ, потребує удосконалення 3 точки зору впровадження математичного апарату та взаємного ув'язування прогнозів тактико-технічних та економічних показників. В сучасних умовах головним напрямком розвитку 30 є поліпшення їх якісних параметрів у ході розробки та виробництва. Як правило, найбільш важливі рішення щодо вибору напрямків розвитку 30 приймаються на ранніх етапах розробки, де особлива роль відводиться прогнозним дослідженням, на основі яких приймається рішення на проектування.

Розгляд перспективних зразків озброєнь пов'язаний 3 прогнозуванням значень показників ï якості. Довгочасне прогнозування потребує врахування умов нестохастичної невизначеності природної, поведінкової та невизначеності мети операції. Особа, яка приймає рішення (ОПР), зацікавлена в тому, щоб з урахуванням фізичного змісту показника якості зразка озброєння, який розглядається, інтервал значень показника відносно того його значення, яке може бути прийнятим як найбільш очікуваним, був би визначений з достатньо високим рівнем довіри.

Враховуючи умови нестохастичної невизначеності, як це наведено в [1-7], довгочасне прогнозування може базуватись на постановці експертизи та обробці експертних даних. Якщо показнику якості зразка озброєння $\alpha_{t}$, який розглядається на момент часу $t$, поставити у відповідність нечітку підмножину $\tilde{\mathrm{A}}_{\mathrm{t}}$, то відповідна іiі функція приналежності з ростом $\mathrm{t}$, буде характеризуватись більшою “розмитістю”, яка свідчить про зростанням часу прогнозування непевності експертів щодо висловлювання своїх суб'єктивних суджень, зростає.

Виникає протиріччя між зростанням непевності експертів при зростанні часу прогнозу та довжиною чіткого інтервалу значень показника якості при прийнятому рівні функції приналежності нечіткої підмножини $\tilde{\mathrm{A}}_{\mathrm{t}}$, який формується при збільшенні іiі “розмитості" та який би задовольняв ОПР.

Таке протиріччя породжує проблему: відповідність фізичної змістовності та “розмитості" функції приналежності нечіткої підмножини, яка відповідає показнику якості зразка озброєння, вимогам ОПР щодо інтервалу його прогнозних значень.

Мета роботи полягає в обгрунтуванні фізичного змісту виду функції приналежності та параметру іiі "розмитості" нечіткої підмножини, яка відповідає показнику якості, та в визначені чіткого інтервалу його прогнозних значень на момент часу $\mathrm{t}$ при прийнятому рівні довіри за значенням функції приналежності.

Для досягнення поставленої мети вирішувалися наступні задачі: проведення порівняльної оцінки багатокритеріальних задач оптимізації, критерії яких можуть відповідати чинникам, що відображають як кількісну, так і якісну ознаку; прогнозування чіткого інтервалу значень показника якості доцільно формувати, яка відповідає нечіткому судженню експертів судженню.

\section{Виклад основного матеріалу дослідження}

Визначення прогнозних значень показника якості зразка озброєння будь-якого фізичного змісту на довгочасну перспективу передбачає врахування умов нечіткого середовища, яке формується природною i поведінковою нестохастичними невизначеностями та невизначеністю мети операції [8]. Прогнозування основується на постановці експертизи, в якій приймають участь $\mathrm{L}$ експертів i кожний $\ell$-й експерт висловлює свою думку незалежно та зворотній зв'язок за схемою експертизи не передбачається.

3 точки зору вирішення визначеної вище проблеми ОПР може виходити 3 того, що чіткий інтервал значень показника якості доцільно формувати при заданому рівні $\alpha$ функції приналежності, яка відповідає судженню “величина $\left|\mathrm{x}_{\mathrm{t}}-\mathrm{a}_{\mathrm{t}}^{(\text {н.о) }}\right|$ є малою”, де $\mathrm{x}_{\mathrm{t}}$ - довільне значення показника якості на момент часу прогнозу $\mathrm{t}, \mathrm{a} \mathrm{a}_{\mathrm{t}}^{\text {(н.о) }} \epsilon$ найбільш очікуване значення показника якості на момент прогнозу $\mathrm{t}$ та відповідає усередненому значенні за результатами опитувань експертів $a_{t}^{\ell(\text { н.о) }}, \ell=\overline{1, L}$. Якщо $a_{t}^{(\text {н.о) }}$ поставити у відповідність нечітку підмножину $\tilde{\mathrm{A}}_{\mathrm{t}}^{(\text {н.о) }}$, то функція приналежності, яка відповідає судженню “величина $\left|\mathrm{x}-\mathrm{a}_{\mathrm{t}}^{(\text {н.о) }}\right| \epsilon$ малою” має вигляд

$$
\mu_{\tilde{\mathrm{A}}_{\mathrm{t}}^{\ell(\text { н.о })}}(\mathrm{x})=\mathrm{e}^{-\mathrm{k}_{\mathrm{t}}\left(\mathrm{x}-\mathrm{a}_{\mathrm{t}}^{\text {(н.о) })}\right)^{2}},
$$

При зростанні часту прогнозу $\mathrm{t}$ умови нестохастичної невизначеності формують невпевненість експертів при висловлюванні їх суб'єктивних думок, яка збільшується. В (1) збільшення невпевненості експертів визначається зменшенням параметра $\mathrm{k}_{\mathrm{t}}$, що відповідає збільшенню “розмитості” функції приналежності.

Відзначимо, що більшим значенням часу прогнозу $\mathrm{t}_{3}>\mathrm{t}_{2}>\mathrm{t}_{1}$ відповідає більша "розмитість" функції приналежності (1), що відповідає збільшенню невпевненості експертів щодо висловлювання своїх суджень.

Вигляд функції приналежності (1) відповідає природному розумінню ОПР щодо значення показника якості: чіткий інтервал прогнозних значень якості визначається як "малий” відносно того значення показника, яке визначається 
експертами на момент прогнозу $\mathrm{t}$ як найбільш очікуваним $\mathrm{a}_{\mathrm{t}}^{(\text {н.о) }}$. При заданому рівні функції приналежності $\alpha$ формуються чіткі інтервали $I_{\tilde{\mathrm{A}}_{\mathrm{t}_{1}}^{(\text {н.о) }}}^{(\alpha)}, \quad \mathrm{I}_{\tilde{\mathrm{A}}_{\mathrm{t}_{2}}^{(\text {н.о) }}}^{(\alpha)}, \quad \mathrm{I}_{\tilde{\mathrm{A}}_{\mathrm{t}_{3}}^{(\text {н.о) }}}^{(\alpha)}$ прогнозних показника якості відповідно на $\mathrm{t}_{3}, \mathrm{t}_{2}, \mathrm{t}_{1}$.

В залежності від змісту фізичної природи показника якості зразка озброєння, ОПР може задовольнити та чи інша довжина інтервалу

$$
\tilde{\mathrm{I}}_{\tilde{\mathrm{A}}_{\mathrm{t}}^{(\text {н.o) }}}^{(\alpha)}=\overline{\overline{\mathrm{I}}}_{\tilde{\mathrm{A}}_{\mathrm{t}}^{(\text {н.o) }}(\alpha)}-\overline{\mathrm{I}}_{\tilde{\mathrm{A}}_{\mathrm{t}}^{(\text {н.o) }}}^{(\alpha)},
$$

де $\overline{\overline{\mathrm{I}}}_{\tilde{\mathrm{A}}_{\mathrm{t}}^{(\alpha)}(\alpha)}^{(\text {н.о) }}, \overline{\mathrm{I}}_{\tilde{\mathrm{A}}_{\mathrm{t}}^{(\alpha) \text { (н) }}}^{(\alpha)} \in$ відповідно кінець та початок інтервалу при рівні функції приналежності $\alpha$ на момент прогнозу t. По сукупності показників якості ОПР приймає рішення щодо доцільного перспективного зразка озброєння у відповідності до умови

$$
\tilde{\tilde{\mathrm{I}}}^{(\alpha)}=\min _{\mathrm{i}} \tilde{\mathrm{I}}_{\tilde{\mathrm{A}}_{\mathrm{i}, \mathrm{t}}^{(\text {H.o) }}}^{(\alpha)},
$$

де $\tilde{\mathrm{A}}_{\mathrm{i}, \mathrm{t}}^{(\text {н.o) }}$ - нечітка підмножина, яка відповідає показнику якості $a_{i, t}^{(\text {н.о) }}$, прогнозне значення якої розглядається на момент прогнозу $\mathrm{t}$.

В залежності від природи показника якості зразка озброєння, параметр $\mathrm{k}_{\mathrm{t}}$ в (1) ОПР може розглядати, як наступні залежності:

$$
\mathrm{k}_{\mathrm{t}}^{(1)}=\mathrm{t}^{-1}, \mathrm{k}_{\mathrm{t}}^{(2)}=\mathrm{e}^{-\mathrm{t}}, \mathrm{k}_{\mathrm{t}}^{(3)}=\left(\mathrm{a}_{\mathrm{t}}^{(\mathrm{o. \Pi )}}-\mathrm{a}_{\mathrm{t}}^{(\text {п) }}\right)^{-1},
$$

де $a_{\mathrm{t}}^{(\text {о.п) }}, \mathrm{a}_{\mathrm{t}}^{(\text {п) }} \epsilon$ відповідно усереднені значення оптимістичної та песимістичної оцінок показника якості $\mathrm{a}_{\mathrm{t}}$ на момент прогнозу $\mathrm{t}$. Тоді при $\mathrm{k}_{\mathrm{t}}=\mathrm{t}^{-1}$ та рівні $\alpha$ функції приналежностей чіткий інтервал $\tilde{\mathrm{I}}_{\tilde{\mathrm{A}}_{\mathrm{t}}^{(\text {н.o) }}}^{(\alpha)}$ має наступне визначення:

\section{Jimepamypa}

1. Більчук В.М. Оцінка ефективності прийняття рішень щодо оперативного управління в умовах нестохастичної невизначеності інформаційного забезпечення / В.М. Більчук, В.І. Ткаченко, Є.Б. Смірнов // Системи озброєння і військова техніка. - 2008. - № 1(13). - С. 2-9. 2. Черноруцкий Г.С. Методы принятия решений / Г.С. Черноруцкий. - СПб.: БХВ-Петербург, 2005. - 416 с. 3. Митихин В.Г. Еще раз о корректности метода анализа иерархий / В.Г Митихин // Материалы IV межд. научнопракт. конференции «Фундаментальные и прикладные науки сегодня». - 2014. - №1. - С. 188-194. 4. Saatya T. (2009). Structures in decision making: On the subjective geometry of hierarchies and networks [on line]. European Journal of Operational Research, vol. 199, is. 3, P. 867-872. 5. Буренок В.М. Развитие военных технологий XXI века: проблемы планирование, реализация / В.М. Буренок, А.В.

$$
\begin{aligned}
& \left\{\overline{\overline{\mathrm{I}}}_{\tilde{\mathrm{A}}_{\mathrm{t}}^{(\text {н.о) }}}^{(\alpha)}\left(\mathrm{k}_{\mathrm{t}}^{(1)}\right)=\mathrm{a}_{\mathrm{t}}^{(\text {н.о) }}+\sqrt{\lambda \mathrm{t}} ; \overline{\bar{A}}_{\tilde{\mathrm{A}}_{\mathrm{t}}^{(\text {н.о) }}}^{(\alpha)}\left(\mathrm{k}_{\mathrm{t}}^{(1)}\right) \mathrm{a}_{\mathrm{t}}^{(\text {н.о) }}-\sqrt{\lambda \mathrm{t}}\right\} ; \\
& \tilde{\mathrm{I}}_{\tilde{\mathrm{A}}_{\mathrm{t}}^{(\text {н.о) }}}^{(\alpha)}\left(\mathrm{k}_{\mathrm{t}}^{(1)}\right)=2 \sqrt{\lambda \mathrm{t}},
\end{aligned}
$$

Аналогічно при $\mathrm{k}_{\mathrm{t}}^{(2)}=\mathrm{e}^{-\mathrm{t}}$ маємо, що

$$
\begin{aligned}
& \left\{\overline{\overline{\mathrm{I}}}_{\tilde{\mathrm{A}}_{\mathrm{t}}^{(\alpha)}}^{(\alpha)}\left(\mathrm{k}_{\mathrm{t}}^{(2)}\right)=\mathrm{a}_{\mathrm{t}}^{(\text {н.о) }}+\sqrt{\lambda \mathrm{e}^{\mathrm{t}}} \div \overline{\mathrm{I}}_{\tilde{\mathrm{A}}_{\mathrm{t}}^{(\text {н.о })}}^{(\alpha)}\left(\mathrm{k}_{\mathrm{t}}^{(2)}\right) \mathrm{a}_{\mathrm{t}}^{(\text {(н.) })}-\sqrt{\lambda \mathrm{e}^{\mathrm{t}}}\right\} ; \\
& \tilde{\mathrm{I}}_{\tilde{\mathrm{A}}_{\mathrm{t}}^{(\text {н.о) }}}^{(\alpha)}\left(\mathrm{k}_{\mathrm{t}}^{(2)}\right)=2 \sqrt{\lambda \mathrm{e}^{\mathrm{t}}},
\end{aligned}
$$

та при $\mathrm{k}_{\mathrm{t}}^{(3)}=\left(\mathrm{I}_{\mathrm{a}_{\mathrm{t}}^{(\text {н.о) }}}\right)^{-1}\left(\mathrm{a}_{\mathrm{t}}^{(\text {о.п) }}-\mathrm{a}_{\mathrm{t}}^{(\text {п) }}\right)^{-1}$ маємо, що:

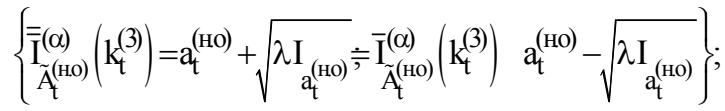

$$
\begin{aligned}
& \tilde{\mathrm{I}}_{\tilde{\mathrm{A}}_{\mathrm{t}}^{(\text {н.о) }}}^{(\alpha)}=2 \sqrt{\lambda \mathrm{I}_{\mathrm{a}_{\mathrm{t}}^{(\text {н.о) }}}}
\end{aligned}
$$

Виходячи із фізичного тлумачення показника якості зразка озброєння ОПР може прийняти рішення щодо чіткого інтервалу прогнозування показника при рівні довіри $\alpha$ один із результатів (5) - (7).

\section{Висновки і перспективи подальших досліджень}

Вимоги ОПР щодо визначення чіткого інтервалу прогнозних значень показника якості зразка озброєння формуються із відповідності фізичної змістовності прийнятої функції приналежності відповідної для цього показника нечіткої підмножини. Довжина інтервалу визначається невпевненістю експертів, які висловлюють свої суб'єктивні судження щодо песимістичної, найбільш очікуваної та оптимістичної оцінок показника якості в умовах нестохастичної невизначеності.
Ивлев. - Тверь: Издательство ООО «КУПОЛ», 2009. - 624 c. 6. Alimpiev A. Selecting a model of unmanned aerial vehicle to accept it for military purposes with regard to expert data/ P. Berdnik, N. Korolyuk, O. Korshets, M. Pavlenko // Eastern-European Journal of Enterprise Technologies ISSN 1729-3774. - № 1/9(85), 2017. - P. 53-60. 7. Korolyuk N. The use of competency-based approach in the project team formation model / A.V. Shmatko, D.Y. Holubnychyi - 13th International Scientific and Practical Conference «Science and Society» - London: SCIEURO, 2018. - C. 12. 8. Королюк Н.О. Вплив інформаційного фактору на тенденції розвитку сучасної збройної боротьби / О.Ю. Пермяков. - Науково-практичнаий семінар кафедри зв'язку та автоматизації «Досвід застосування частин та підрозділів зв'язку в АТО на Сході України» - К.: НУОУ, 2018. - C. 26-28.

\section{ПОДХОД ПО ПРОГНОЗИРОВАНИЮ ПОКАЗАТЕЛЕЙ КАЧЕСТВА ПЕРСПЕКТИВНЫХ ОБРАЗЦОВ ВООРУЖЕНИЙ В УСЛОВИЯХ НЕСТОХАСТИЧЕСКОЙ НЕОПРЕДЕЛЕННОСТИ}


Наталья Александровна Королюк (кандидат технических наук) ${ }^{1}$ Сергей Николаевич Листровой ${ }^{2}$ Николай Игоревич Щербаков ${ }^{3}$

\author{
${ }^{1}$ Харьковский национальный университет Воздушных Сил им. И. Кожседуба, Харьков, Украина \\ 2 в/ч А2100, Киев, Украина \\ ${ }_{\text {в }}$ ч А0334, Днепр, Украина
}

\begin{abstract}
Рассматривается долговременное прогнозирование показателей качества образиов вооружения в условиях нечеткой среды, которое формируется естественной, поведенческой нестохастической неопределенностью и неопределенностью иели операџии. Функиию принадлежности ЛПР определяет исходя из ее соответствия физическому содержанию показателя. Численная мера неуверенности экспертов относительно высказывания своих субъективных мнений определяется параметром функиии принадлежности, который описывает ее “размытость”. В качестве интервала прогнозных значений предлагаются четкие подмножества носителей значений показателей. Обосновано физическое содержание вида функиии принадлежности и параметра ее “размытости” нечеткого множества, которое соответствует рассматриваемому показателю качества.
\end{abstract}

Ключевые слова: долговременное прогнозирование, показатели качества, образцы вооружений, нестохастическая неопределенность.

\title{
IN FORECASTING OF LONG DURATION PROGNOSTICATION OF INDEXES OF QUALITY OF PERSPECTIVE STANDARDS OF ARMAMENTS IN THE CONDITIONS OF UNSTOCHASTIC VAGUENESS
}

\author{
Nataliia Koroliuk (Candidate of technical sciences) ${ }^{1}$ \\ Serhii Listrovyj ${ }^{2}$ \\ Mykola Shcerbakov ${ }^{3}$ \\ ${ }^{1}$ Ivan Kozhedub Kharkiv National Air Force University (KNAFU), Kharkov, Ukraine \\ ${ }^{2}$ Military base A2100, Kiev, Ukraine \\ ${ }^{3}$ Military base A0334, Dnieper, Ukraine
}

The process of determining the predictive values of the quality indicator of a weapon of a weapon for a long-term perspective, which involves taking into account the conditions of the fuzzy environment, which is formed by natural and behavioral non-stochastic uncertainties and uncertainty of the purpose of the operation. The membership function determines the person making the decision on the basis of its compliance with the physical content of the indicator. The numerical measure of the uncertainty of experts regarding the expression of their subjective thoughts is determined by the attribute function parameter, which describes its "blurriness". As a range of predictive values, clear subsets of carriers of the values of indicators are offered. The physical content of the form of the function of belonging and the parameter of its "blurriness" of the fuzzy subset, which corresponds to the quality indicator being considered, and the definite clear interval of its predictive values at the time with the accepted level of trust by the value of the membership function is substantiated.

Keywords: of long duration prognostication, indexes of quality, standards of armaments, unstochastic vagueness.

\section{References}

1. Bilchuk V.M., Tkachenko V.I., Smirnov Ye.B.(2008), Estimation of decision-making efficiency in operational management in the conditions of non-stochastic uncertainty of information provision [Otsinka efektyvnosti pryiniattia rishen shchodo operatyvnoho upravlinnia $\mathrm{v}$ umovakh nestokhastychnoi nevyznachenosti informatsiinoho zabezpechennia] Systemy ozbroiennia i viiskova tekhnika, No. 1(13), pp. 2-9. 2. Chernorutskiy G.S., (2005), Decision making methods [Metodyi prinyatiya resheniy] BHVPeterburg, Saint Petersburg, 416 p. 3. Mitihin V.G., (2014), Once again about the correctness of the hierarchy analysis method, [Esche raz o korrektnosti metoda analiza ierarhiy] Fundamentalnyie i prikladnyie nauki segodnya, No. 1, 188194 pp. 4. Saatya T. (2009), Structures in decision making: On the subjective geometry of hierarchies and networks, [Strukturyi $\mathrm{v}$ prinyatii resheniy: o sub'ektivnoy geometrii ierarhiy i setey] European Journal of Operational Research, vol. 199, is. 3, p. 867-872. 5. Burenok V.M., (2009), The development of military technology of the XXI century: problems of planning, implementation, [Razvitie voennyih tehnologiy XXI veka: problemyi planirovanie, realizatsiya] KUPOL, Tver, 614 p. 6. Alimpiev A., Berdnik P., Korolyuk N., Korshets O., Pavlenko M., (2017), Selecting a model of unmanned aerial vehicle to accept it for military purposes with regard to expert data [Vyibor modeli bespilotnogo letatelnogo apparata dlya ispolzovaniya ego $\mathrm{v}$ voennyih tselyah $\mathrm{s}$ uchetom dannyih ekspertov] Eastern-European Journal of Enterprise Technologies, №1/9 (85), p. 53-60. 7. Korolyuk N. (2018), The use of competency-based approach in the project team formation model [Ispol'zovaniye kompetentnostnogo podkhoda $\mathrm{v}$ modeli formirovaniya komandy proyekt] London, Scieuro, p. 12. 8. Korolyuk N., (2018), Inflating the information factor to the trend of development of a successful battle [Vpervyye informatsionnyy fakt o tenderakh rozovogo suchnooblast] - Seminar of the department of titles and automation "Private and partial visits to the ATO in Ukraine", p. 26-28. 